\title{
SYNAPTIC EXCITATORY AND INHIBITORY INTERACTIONS AT DISTAL DENDRITIC SITES ON MITRAL CELLS IN THE ISOLATED TURTLE OLFACTORY BULB ${ }^{1}$
}

\author{
KENSAKU MORI, ${ }^{2}$ MARTHA C. NOWYCKY, AND GORDON M. SHEPHERD ${ }^{3}$ \\ Section of Neuroanatomy, Yale University School of Medicine, New Haven, Connecticut 06510
}

Received November 23, 1983; Revised March 6, 1984; Accepted March 7, 1984

\begin{abstract}
The olfactory nerves terminate exclusively on the distal dendritic tufts of mitral cells in the olfactory bulb, which makes this a favorable model for analysis of synaptic responses in distal dendrites. Intracellular recordings of responses to olfactory nerve volleys have been obtained in the isolated turtle olfactory bulb. Single mitral cells usually responded with excitatory postsynaptic potentials (EPSPs) to volleys in two different bundles, indicating convergence from separate receptor neuron populations. Paired volleys revealed long-lasting inhibition of a test EPSP by a conditioning volley. This could be shown to be independent of the inhibition of mitral cells by granule cell interneurons in the deeper layers. The results suggest that excitatory and inhibitory synaptic interactions in the glomerular layer are important in the processing of olfactory inputs. The results also provide an exception to the classical doctrine that synaptic inhibition is preferentially sited near the cell body and axon hillock in order to control impulse generation there. Our findings of inhibitory actions on distal dendrites of mitral cells may provide a model for similar actions on distal dendrites of other central neurons.
\end{abstract}

Neurons in the vertebrate central nervous system typically receive specific synaptic input on restricted portions of their dendrites or cell bodies. The relative positions of these different synaptic inputs are important factors for synaptic integration in the neuron (Rall, 1977; Shepherd, 1979).

In mitral cells of the vertebrate olfactory bulb, olfactory nerve $(O N)$ input is rigidly restricted to a distal tuft of the primary dendrites in the glomeruli. In the isolated turtle olfactory bulb preparation, this $\mathrm{ON}$ input can be easily and selectively activated by a volley in an isolated $\mathrm{ON}$ bundle (Waldow et al., 1981). Because of the ability to stimulate all of the ONs which converge onto mitral cells in this preparation, together with the relatively effective electrotonic spread along the primary dendrites, the input from ONs to the distal dendrites can be recorded as a robust excitatory postsynaptic potential by a recording micropipette within the mitral cell soma (Mori et al., 1981b).

In addition to the distal excitatory input, mitral cells are known to receive synaptic inputs on different portions of their dendritic processes from two kinds of intrinsic neurons. Best understood are the synaptic inputs from granule cell dendrites, which are distributed on the mitral secondary dendrites, proximal portions of the primary dendrites, and the mitral cell

\footnotetext{
${ }^{1}$ This work was supported by Grants NS-07609 and NS-19174 from the National Institute for Neurological and Communicative Disorders and Stroke.

2 Present address: Department of Physiology, Gunma University School of Medicine, Showa-Machi, Maebashi, Gunma, 371, Japan.

${ }^{3}$ To whom correspondence should be addressed.
}

bodies (Price and Powell, 1970). These dendrodendritic synaptic inputs from the granule cells are known to be inhibitory (Phillips et al., 1963; Yamamoto et al., 1963; Rall and Shepherd, 1968; Nicoll, 1969; Mori and Takagi, 1978; Mori et al., 1981b; Jahr and Nicoll, 1982). Granule cells can be activated by a volley in the mitral cell axons in the lateral olfactory tract (LOT) or a volley in the ON (Mori and Shepherd, 1979; Mori et al., 1981b; Jahr and Nicoll, 1982). In contrast, the other main type of intrinsic neuron-the periglomerular (PG) short-axon cell-is strongly excited by ON volleys but is either unaffected or weakly inhibited by LOT volleys (Shepherd, 1963). The PG cell makes dendrodendritic and axodendritic synapses exclusively onto the distal portions of the mitral primary dendrites in the glomerular layer (Hinds, 1970; Reese and Brightman, 1970; Pinching and Powell, 1971; White, 1972). The evidence thus far is that, like the granule cells, the $\mathrm{PG}$ cells inhibit mitral cells through these synapses (Shepherd, 1971; Getchell and Shepherd, 1975).

Thus, mitral cells in the isolated turtle olfactory bulb provide an excellent opportunity for study of interactions between different synaptic inputs mediated by distinct interneuronal populations onto different portions of the neuronal dendritic tree.

In a previous report on the isolated turtle olfactory bulb, we studied several components of the intracellularly recorded synaptic potentials of mitral cells following stimulation of either the ONs or the LOT (Mori et al., 1981b, c). In the present study, we report analysis of interactions between distal synaptic responses to separate excitatory $O N$ inputs, and between these and the proximal and distal inhibitory responses mediated by local neuronal circuits within the bulb. 


\section{Materials and Methods}

The experiments have been carried out on the olfactory bulb of the turtle, Pseudemys scripta. The preparation of the in vitro olfactory bulb and the methods for stimulating and recording have been fully described elsewhere (Mori et al., 1981a). Intracellular recordings were obtained from mitral cells lying mainly in the ventral portion of the olfactory bulb. In most cases, a suction electrode was used to stimulate the whole ventral $O N$. In seven experiments, however, the ventral ON was gently dissected apart into two small bundles, and bipolar silver electrodes were placed on each of the separated bundles. Shocks to the nerve were repeated very slowly to avoid long-lasting effects on $\mathrm{ON}$ excitability; the stimulus intervals for single or paired shocks were usually 2 or $4 \mathrm{sec}$. The strength of ON volley was adjusted to be just supramaximal for eliciting the large positive field potential in the granule cell layer (the responses in period III described by Waldow et al., 1981). The recording micropipettes were filled with $2 \mathrm{M}$ potassium acetate and had DC resistances between 40 and 100 megohms.

\section{Results}

Cunvergence of $O N$ inputs on a single mitral cell. A characteristic feature of the synaptic input of the ONs to the mitral (and tufted) cells is a large convergence at the glomerular tuft (Allison, 1953; Ramón y Cajal, 1955). To test whether a single mitral cell receives these converging inputs from olfactory axons running in different $O N$ bundles, the ventral $O N$ was dissected into two small bundles $\left(\mathrm{ON}_{1}\right.$ and $\left.\mathrm{ON}_{2}\right)$. We then recorded intracellularly the responses of mitral cells to $O N_{1}$ and $\mathrm{ON}_{2}$ stimulation. Mitral cells were identified by their antidromic spike responses (Fig. $1 B$ ) or a characteristic sequence of inhibitory potentials (see Mori et al., 1981a, b) following LOT stimulation. The records shown in Figure $1, B$ to $D$, were obtained from a typical cell. A single volley in $\mathrm{ON}_{1}$ elicited an initial depolarization ( $\mathrm{E}_{1}$ component, arrow) with a spike potential (Fig. 1C). $\mathrm{ON}_{2}$ stimulation also elicited an $\mathrm{E}_{1}$ component but without any spike potential within the range of stimulus intensities used (Fig. 1D). Recordings from another cell are shown in Figure $1, E$ and $F$. In this mitral cell, an $\mathrm{E}_{1}$ component with a superimposed spike was elicited by the $\mathrm{ON}_{2}$ volley (Fig. $1 F$ ) as well as the $\mathrm{ON}_{1}$ volley (Fig. $1 E$ ). The $\mathrm{E}_{1}$ component is the EPSP elicited in the glomcrular dendritic branches by the ON synapses (Mori et al., 1981b); therefore, the above results indicate that these mitral cells receive $O N$ inputs from both nerve bundles $\left(\mathrm{ON}_{1}\right.$ and $\left.\mathrm{ON}_{2}\right)$. In nine mitral cells which showed convergence of excitatory synaptic inputs from $\mathrm{ON}_{1}$ and $\mathrm{ON}_{2}$, four cells responded with an action potential to both $\mathrm{ON}_{1}$ and $\mathrm{ON}_{2}$ volleys, three cells showed an action potential following either $\mathrm{ON}_{1}$ or $\mathrm{ON}_{2}$ volley, and the remaining two cells did not show any action potentials to either of the volleys within the range of stimulus intensities used.

Effects of conditioning $O N$ volleys. The interactions of synaptic potentials in mitral cells were studied using paired $O N$ volleys. An example is shown in Figure $2, A$ and $B$. In Figure $2 A$, seven traces were superimposed. After a conditioning volley, testing $O N$ volleys were applied at different intershock intervals (indicated in Fig. 2 by arrows $b$ to $e$ ). It can be seen that the testing $\mathrm{ON}$ volleys failed to elicit an action potential and that the shape of the synaptic response to a test volley changed with changes in the conditioning-test intervals.

In Figure $2 B$, the oscilloscope was triggered by both the conditioning and the test volley, and the responses to each volley were compared with a fast sweep speed. In each figure, the response to the conditioning volley is shown in the upper trace. A conditioning volley always elicited a spike potential arising from an EPSP ( $\mathrm{E}_{1}$ component). The spike was followed by a series of inhibitory and excitatory potentials $\left(\mathrm{I}_{1}, \mathrm{E}_{2}, \mathrm{I}_{2}\right.$, and $\mathrm{I}_{3}$ components, as indicated by arrows in Fig. $2, A, B a$, and $B b$; cf. Mori et al., $1981 \mathrm{~b}, \mathrm{c}$ ). The traces of the test responses (indicated by an asterisk) start below the conditioning responses (because of the prolonged hyperpolarization ( $\mathrm{I}_{3}$ component) elicited by the conditioning volley). With conditioningtest intervals of $300 \mathrm{msec}$ (Fig. $2 \mathrm{Ba}$ ) and $400 \mathrm{msec}$ (Fig. $2 B b$ ), the spike of the test response was blocked, and the initial depolarization ( $\mathrm{E}_{1}$ component) showed a slower rising and falling phase. The $I_{1}$ and $I_{2}$ components of the test response were not seen clearly. When the conditioning-test interval was lengthened (Fig. $2 B, d$ and $e$ ), the rising phase of the initial depolarization became steeper, and the depolarization was cut short by a hyperpolarizing potential. With further increase in the conditioning-test intervals ( $\mathrm{Fig} .2 B f, 2 \mathrm{sec}$ ), the $\mathrm{E}_{1}$ compo-
A

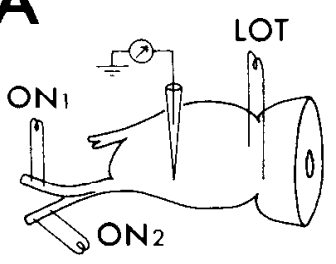

B

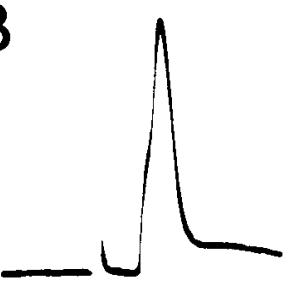

msec

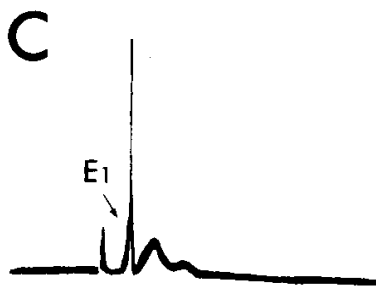

D

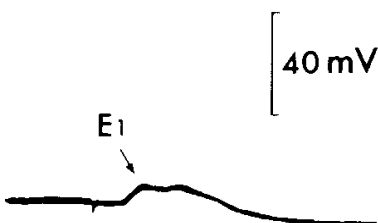

msec
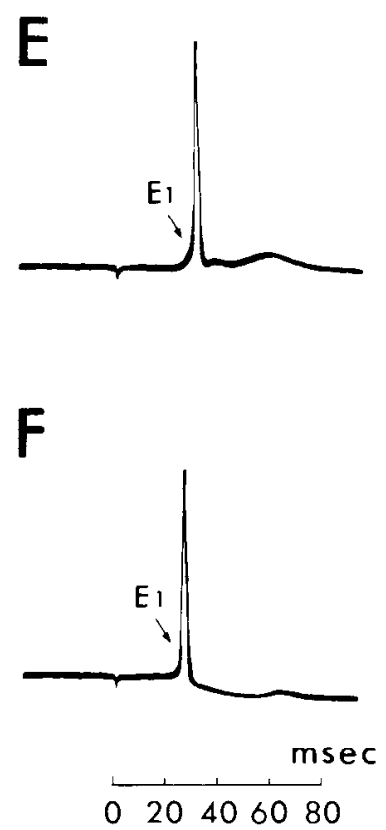

Figure 1. Convergence of ON inputs onto single mitral cells. $A$, Schematic diagram of the experimental set up. $\mathrm{ON}_{1}, \mathrm{ON}_{2}$, separate $\mathrm{ON}$ bundles. $B$, Antidromic response of a mitral cell to a LOT volley. $C$ and $D$, Orthodromic responses of the same cell to a volley in $\mathrm{ON}_{1}(C)$ and $O N_{2}(D)$. $E$ and $F$, Another mitral cell responding to an $\mathrm{ON}_{1}$ volley $(E)$ and $O N_{2}$ volley $(F)$. $E_{1}$ indicates the EPSP component of the ON-evoked responses. 


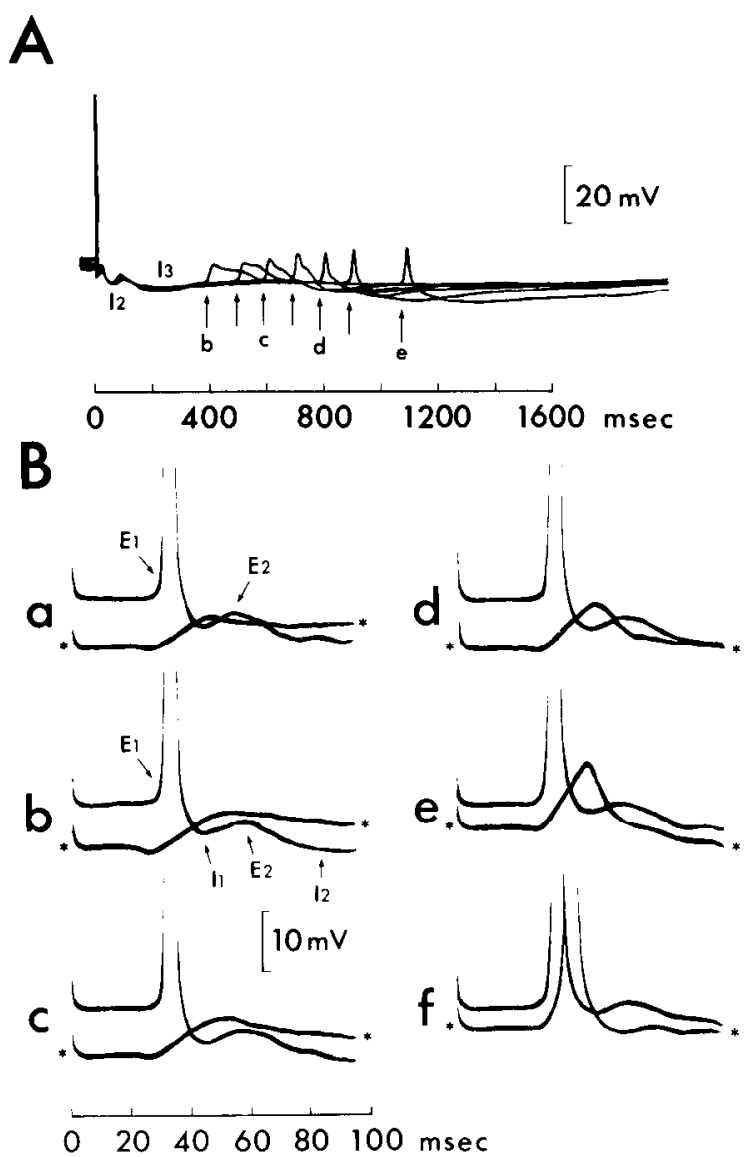

Figure 2. Effects of conditioning $\mathrm{ON}$ volley on the mitral cell response to the test $\mathrm{ON}$ volley. $A$, Superimposed tracings of the mitral cell responses to paired $\mathrm{ON}$ volleys of equal intensity at seven different intershock intervals. The times of test $O N$ volleys are indicated by arrows. $I_{2}$ and $I_{3}$ in $A$ indicate the $\mathrm{I}_{2}$ and $\mathrm{I}_{3}$ components of the mitral cell response elicited by the conditioning $\mathrm{ON}$ volley. $B$, Comparison of the mitral cell responses to the conditioning ON stimulation (upper traces) and the test $\mathrm{ON}$ volley (lower traces indicated by asterisk). The control and test responses were superinposed with a fast sweep speed. The test responses in $B b, B c, B d$, and $B e$ correspond to the test responses in $A$ (indicated by arrows with corresponding letters $b, c, d$, and $e$ ). The components of the control ON response are indicated by $E_{1}, E_{2}, I_{1}$, and $I_{2}$ in $B a$ and $B b$.

nent of the test response increased in amplitude and finally gave rise to an action potential. Note in Figure $2 B f$ that the test response still starts from a slightly hyperpolarized membrane potential level and that the $\mathrm{E}_{2}$ component is still depressed. In almost all of the mitral cells ( 25 of 26 cells) tested with the above method, the conditioning (just supramaximum) ON volley depressed all of the components $\left(\mathrm{E}_{1}, \mathrm{E}_{2}, \mathrm{I}_{1}, \mathrm{I}_{2}\right.$, and $\mathrm{I}_{3}$ ) of the test responses, although the degree and the time course of the depression of each component varied somewhat from cell to cell.

Time course of the depression of the test $E_{1}$ component. Since the $\mathrm{E}_{1}$ component is known to be an excitatory synaptic potential generated by $\mathrm{ON}$ synapses in the terminal tuft of the mitral cell, it represents a distal synaptic input in the mitral cell. We have analyzed in detail the effect of a conditioning ON volley on the amplitude of this component. In most mitral cells, accurate measurement of the amplitude was difficult because of the superimposed action potential (Fig. 2). However, in four mitral cells with relatively high resting membrane potentials, it was possible to clicit the $E_{1}$ component without the action potential. In these cells, the peak amplitude was measured at various times after the conditioning $\mathrm{ON}$ volley. Figure $3 B$ shows a typical example. When a small background depolarizing DC current was injected (Fig. $3 B c$ ), this cell showed the synaptic response with superimposed spike that was typical of mitral cells (Figs. 1 and 2).

Figure $3 B a$ shows the responses to conditioning and testing ON volleys of equal stimulus intensity. These responses are shown superimposed on faster sweeps in Figure $3 B b$. The amplitudes of the $E_{1}$ components of the conditioning and test responses were measured at the times indicated by the dashed line in Figure $3 B b$. The relative amplitude of the test response is plotted at different test intervals in Figure $3 A$. The depression of the $\mathrm{E}_{1}$ component had a complicated time course at the intershock intervals between 0 and $200 \mathrm{msec}$. With an intershock interval of $200 \mathrm{msec}$, the amplitude of the $\mathrm{E}_{1}$ component was reduced to approximately $40 \%$ of the control response. With increase in the intershock interval, the amplitude of the test $E_{1}$ component recovered gradually. The depression was present for a long time (up to about $1500 \mathrm{msec}$ in this example) after the conditioning volley. In three other experiments a longlasting depression ( 1 to $3 \mathrm{sec}$ ) of the $\mathrm{E}_{1}$ component similar to that described above was found.

One of the possible causes of this depression could be an increase in membrane conductance of the soma and/or secondary dendrites of the recorded mitral cell, due to the IPSPs $\left(I_{1}\right.$, $I_{2}$, and $I_{3}$ component) elicited by the conditioning volley. To check this, we have measured the time course of the membrane conductance change following the conditioning volley. The membrane conductance change was measured in the usual way, as a change in the amplitude of the voltage transient produced by injecting current pulses through the recording microelectrode using a bridge-balance circuit (Mori et al., 1981b, c). As shown by the open circles and dashed line in Figure $3 A$, an increase in membrane conductance was present for only a relatively brief period (about $150 \mathrm{msec}$ ) after the conditioning ON volley. After that, no increase in the membrane conductance was detected despite the great depression of the $E_{1}$ component of the test $O N$ response.

Effect of conditioning LOT stimulation on the test ON-evoked $E_{1}$ component. Since supramaximal LOT stimulation elicits inhibitory potentials $\left(\mathrm{I}_{1}, \mathrm{I}_{2}\right.$, and $\mathrm{I}_{3}$ components) which are similar to those evoked by the ON stimulation (Mori al., $1981 \mathrm{~b}, \mathrm{c})$, we have examined the effect of a conditioning LOT volley on the responses to the test $\mathrm{ON}$ volley. In most mitral cells, a conditioning LOT volley blocked the test ON-evoked spike response. However, the amplitude of the $E_{1}$ component was not depressed by the conditioning LOT stimulation. An example of the effect of the $\mathbf{E}_{1}$ component is shown in Figure 4. For comparison, the effect of the conditioning ON volley in this cell is shown in Figure 4, $A a$ and $A b$. Note the depression of the $E_{1}$ component. In contrast, the amplitude of this component was not depressed by a conditioning LOT stimulation (see Fig. $4, B a$ and $B b$ ), despite the large IPSP elicited by the conditioning LOT volley. The difference in the effect between the conditioning $\mathrm{ON}$ volley and the conditioning LOT volley is clearly seen in the superimposed tracings in Figure $4 C$. The $\mathrm{E}_{1}$ and $\mathrm{E}_{2}$ components of the test response were not depressed by a conditioning LOT volley and were even slightly increased in amplitude (dotted line in Fig. $4 \mathrm{C}$ ). In contrast, a conditioning ON volley greatly depressed the $E_{1}$ component and almost completely suppressed the $\mathrm{E}_{2}$ component of the test response (Fig. $4 C$, dashed line).

\section{Discussion}

Convergence of distal excitatory inputs. 'The present results indicate the convergence onto a single mitral cell of excitatory synaptic input from ONs running in different $O N$ bundles. Since the different $\mathrm{ON}$ bundles are likely to arise from olfactory receptor cells located in spatially different portions of the 


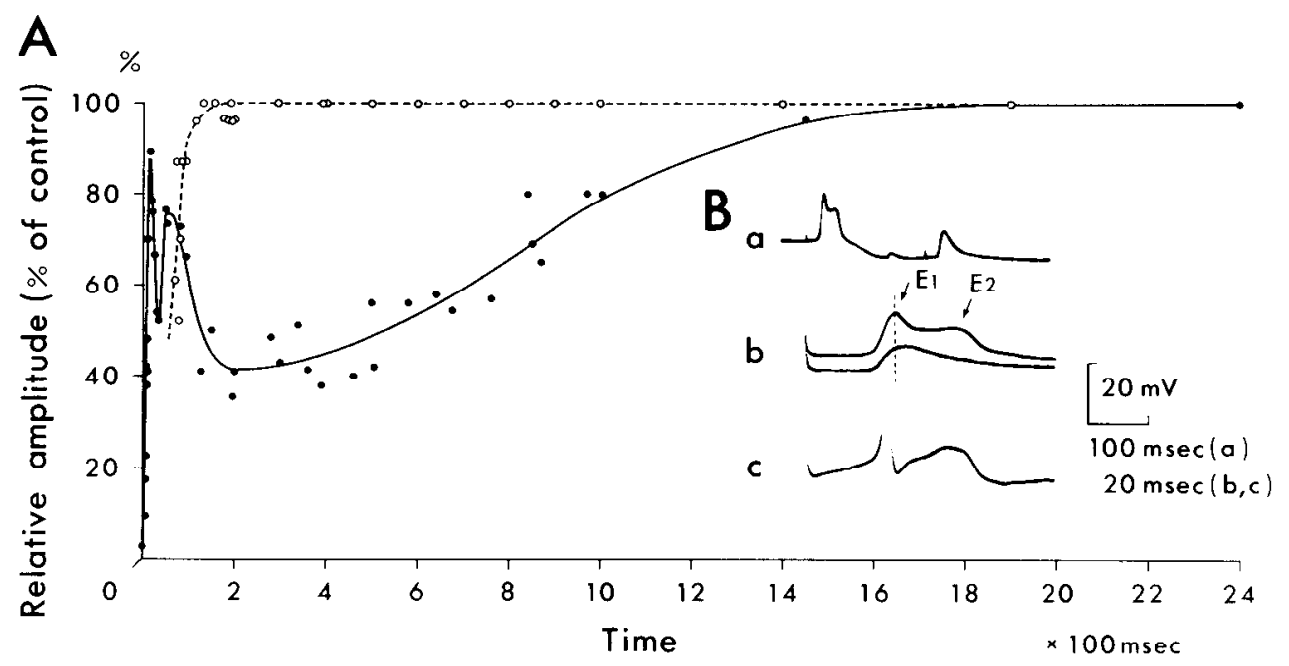

Figure 3. A, Comparison of the time course of the suppression of the $\mathrm{E}_{1}$ component of the test $\mathrm{ON}$ evoked response (solid circle and solid line) with that of the changes in the membrane conductance (open circle and broken line) of the mitral cell following the conditioning $\mathrm{ON}$ volley. Ordinate, the relative amplitude of the $\mathrm{E}_{1}$ component of the test $\mathrm{ON}$ response (solid circle) and that of the voltage drop produced by a hyperpolarizing current pulse $(0.25 \mathrm{nA}$ and $50 \mathrm{msec}$ in duration) injection following the conditioning $\mathrm{ON}$ volley. They are calculated as percentages of the control (unconditioned) responses. $B a$, An example of the responses to the paired $O N$ volley. $B b$, The same responses as in $B a$ were superimposed with a faster sweep speed (DC recording). $B c$, The response of the same mitral cell to the $\mathrm{ON}$ volley during a small $(0.1 \mathrm{nA})$ depolarizing current injection.

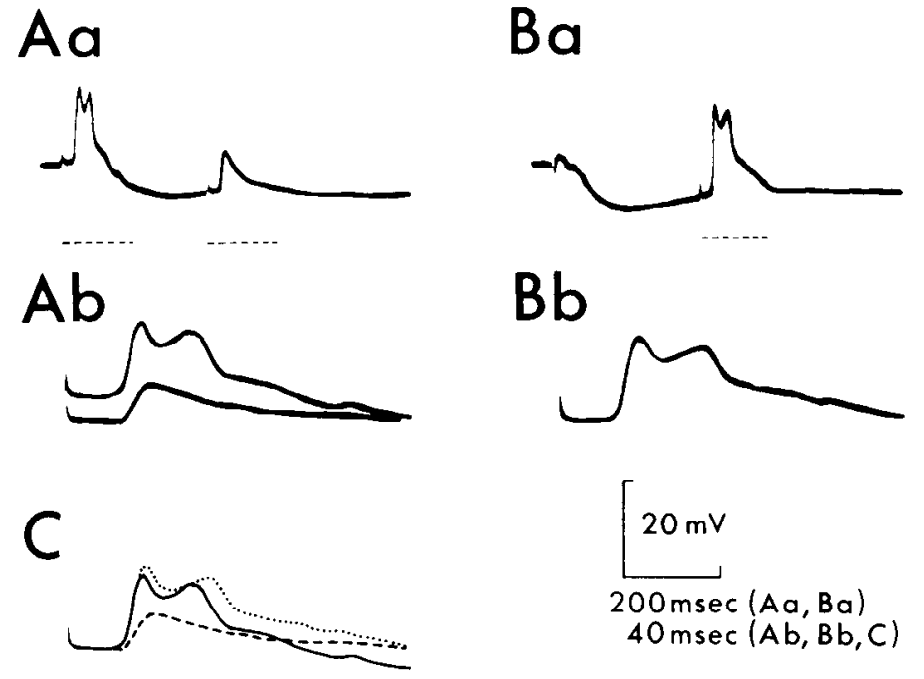

Figure 4. Comparison of the effect of the conditioning LOT volley with the conditioning $O N$ volley on the test $O N$-evoked response. $A a$ and $A b, O N$ volley was applied as a conditioning stimulation. $B a$ and $B b$, Conditioning LOT volley. The responses to the ON volleys (indicated by dashed underlines in $A a$ and $B a$ ) were shown with a faster sweep speed in $A b$ and $B b$, respectively. $C$, The control $\mathrm{ON}$-evoked response (solid line), the test $\mathrm{ON}$-evoked response following conditioning LOT volley (dotted line), and the test $\mathrm{ON}$-evoked response following the conditioning $\mathrm{ON}$ volley (dashed line) were superimposed for the comparison of the amplitude of the $\mathrm{E}_{1}$ component.

olfactory epithelium (Allison, 1953; Land, 1973; Land and Shepherd, 1974; Kauer, 1981), a single milral cell may, thus, receive synaptic input from spatially distributed receptors in the olfactory epithelium. It is possible that convergence of the $\mathrm{ON}$ inputs from different $\mathrm{ON}$ bundles onto a given mitral cell occurs in one glomerulus. However, in the turtle olfactory bulb, mitral cells typically have more than one primary dendrite, each of which terminates in widely separated glomeruli (Mori et al., 1981a). Consequently, it is possible that olfactory axons from different $\mathrm{ON}$ bundles terminate on different primary dendrites of a mitral cell.

Inhibition of distal excitatory responses. Waldow et al. (1981) reported that in the isolated turtle olfactory bulb, conditioning ON volleys cause a prolonged suppression of the summed synaptically evoked potentials and spike responses of mitral cells to a test ON volley (see also Orrego, 1961, and Iwase and Lisenby, 1965 for in vivo preparation). In agreement with this, the present study has shown a prolonged suppression of all of the components $\left(E_{1}, E_{2}, I_{1}, I_{2}\right.$, and $I_{3}$ ) of the intracellularly recorded synaptic responses of mitral cells by a conditioning ON volley,

The $\mathrm{E}_{1}$ component is an EPSP elicited monosynaptically at the terminal tuft of the mitral cell primary dendrites (Mori et al., 1981b; Nowycky et al., 1981). We have analyzed in detail the suppression of the $\mathrm{E}_{1}$ component by conditioning $\mathrm{ON}$ and LOT volleys, in order to gain insight into the properties of these synapses and their relation to the local circuits of the olfactory bulb.

In the paired $\mathrm{ON}$ volley experiments, the $\mathrm{E}_{1}$ component typically showed early partial recoveries followed by a prolonged suppression which lasted more than $1 \mathrm{sec}$ (Figs. 2 and 3). Similar recovery cycles have been described for the period II activity of the summed ON-evoked potentials, which were interpreted as the synaptic excitatory and impulse response of mitral (and tufted) cells to an ON volley (Waldow et al., 1981).

In a previous study (Mori et al., 1981b), we have shown that the inhibitory $I_{2}$ component (and possibly also $I_{1}$ ) of the $O N$ evoked synaptic potentials is associated with a large increase in the membrane conductance of the mitral cell. Thus, one of the possible causes of the suppression of the $\mathrm{E}_{1}$ component is a shunting effect of the conductance increase in the mitral cell membrane accompanying the $I_{1}$ and $I_{2}$ components. However, the time cQurse of suppression of the $\mathrm{E}_{1}$ component was quite different from that of the conductance increase (Fig. 3 ). The suppression of the $\mathrm{E}_{1}$ component typically lasted more than 1 sec, while the duration of the membrane conductance increase (measured at the soma) varied in different cells between 100 msec and $1.5 \mathrm{sec}$ (typically less than $400 \mathrm{msec}$; cf. Mori et al., 1981c). Consequently the conductance increase accompanying 
the $I_{1}$ and $I_{2}$ components of the conditioning response cannot explain the long-lasting nature of the suppression of the $\mathrm{E}_{1}$ component.

To examine further the above conclusion, we have used a conditioning LOT volley. LOT stimulation also elicits responses with $\mathrm{I}_{1}$ and $\mathrm{I}_{2}$ components quite similar to the $\mathrm{ON}$ evoked component (Mori et al., 1981b). In agreement with the above conclusion, the conditioning LOT volley did not suppress the amplitude of the $E_{1}$ component of the test $O N$-evoked response (Fig. 4). The $I_{1}$ and $I_{2}$ components of the $O N$ - and LOT-evoked responses have been suggested to represent initial and delayed activation of granule-to-mitral dendrodendritic inhibitory synapses (Mori et al., 1981b). These components occur mainly in secondary dendrites, proximal portions of primary dendrites, and somata of the mitral cells. Thus, the sites of membrane conductance increases accompanying the $I_{1}$ and $\mathrm{I}_{2}$ components are spatially separated from the sites of the $\mathrm{E}_{1}$ component generation in the glomeruli. This explains the lack of suppression of the $\mathrm{E}_{1}$ component by conditioning LOT stimulation. The marked suppression of the $\mathrm{E}_{1}$ component by conditioning $\mathrm{ON}$ stimulation, by contrast, suggests that the ON volley activates an additional inhibitory membrane conductance at or near the generation sites of the $\mathrm{E}_{1}$ component, i.e., at or near the distal portions of the primary dendrites of mitral cell.

Intrinsic circuits mediating distal dendritic inhibition. As we have noted, an advantage of the olfactory bulb is that, in attempting to identify neuronal processes contributing to intrinsic circuits, one is aided considerably by the sharp histological lamination and localization of neurons and their synapses in separate layers. Within the glomerular layer, the main candidates for intrinsic elements are the PG cells. Morphological studies have shown that the PG cells receive type I (presumably excitatory) synapses from olfactory nerve terminals as well as from mitral and tufted cell dendrites (Andres, 1970; Hinds, 1970; Reese and Brightman, 1970; Pinching and Powell, 1971; Shepherd, 1972; White, 1972). As discussed in the introduction, physiological studies have shown that $\mathrm{PG}$ cells are, in fact, excited by these inputs and have provided evidence that the PG cell dendrites are, in turn, inhibitory onto the mitral and tufted cells at their terminal dendritic tufts in the glomerular layer (Shepherd, 1971; Getchell and Shepherd, 1975).

This close correlation of morphology and physiology does not rule out other mechanisms which might contribute to the results. One possibility is that a conditioning ON volley caused a prolonged suppression of transmitter release at the terminal arborizations of the $\mathrm{ON}$ fibers within the glomeruli. It is unlikely that this would come about by presynaptic inhibition, since no synaptic contacts have been observed on the terminal portions of the ON axons (Pinching and Powell, 1971). A generalized effect on the excitability of the presynaptic terminals, as by accumulation of extracellular $K$, is another possibility. A referee pointed out the possibility that "impulse conduction failure in the terminal arborization of olfactory nerve axons may contribute to the observed suppression of the $\mathrm{E}_{1}$ component." This would be by analogy with the failing of transmission that has been postulated to occur in branches of Ia fibers to motoneurons in responses to single volleys and the more extensive transmission, and hence larger EPSP, that occurs during post-tetanic potentiation (Lüscher et al., 1983). Such a mechanism is less likely in the present case, because of the lack of axonal branching (the $\mathrm{ON}$ axon is believed not to branch before reaching its target glomerulus and arborizes sparingly within the glomerulus (see Land and Shepherd, 1974)); the avoidance of conditioning tetanization; the use of very long interstimulus intervals ( 2 and 4 sec; see "Materials and Methods"); and the contrast between post-tetanic potentiation of EPSPs in the motoneuron and postconditioning suppression of EPSPs in the mitral cell. Further experiments will be required to test adequately for the contributions of these and other possible mechanisms to the present results.

The distal local circuit inhibition at or near the terminal tuft of the mitral cell primary dendrites is likely to play an important role in synaptic integration within the glomerulus and control of transmission through the mitral cells (Shepherd, 1977, 1979). At the terminal tuft, there is a convergence of a large number of excitatory ON inputs (Allison, 1953; Ramón y Cajal, 1955). In addition, prolonged synaptic excitation of unknown origin occurs at or near the terminal tuft (Nowycky et al., 1982). These distal excitatory inputs are combined with the distal local inhibition shown in the present study; this local synaptic integration provides the basis for the initial processing of the olfactory input. Thus, the mitral cell provides a model for the integrative function of synaptic inhibition at distal dendritic sites, as is also found in crustacean receptor cell dendrites (Kuffler and Eyzaguirre, 1955). These stand in contrast to the more widely known examples of inhibitory inputs at or near the cell body, as in motoneurons (Eccles, 1964) or Purkinje cells (Eccles et al., 1967). The synaptic potentials in the glomerular tuft are the outcome of this complex distal integration and constitute the functional link for transmission to the mitral cell body. Contributing to this linkage are dendritic spike generation (Mori et al., 1982) and dendrodendritic synaptic output from the mitral cell primary dendrites.

\section{References}

Allison, A. C. (1953) The morphology of the olfactory system in the vertebrates. Biol. Rev. 28: 195-244.

Andres, K. H. (1965) Der Feinbau des Bulbus Olfactorius der Ratte unter besonderer Berücksichtigung der synaptischen Verbindungen. Z. Zellforsch. 65: 530-561.

Andres, K. H. (1970) Anatomy and ultrastructure of the olfactory bulb in fish, amphibia, reptiles, birds, and mammals. In CIBA Foundation Symposium on Taste and Smell in Vertebrates, G. E. W. Wolstenholme and J. Knight, eds. pp. 177-194, Churchill, London.

Eccles, J. C. (1964) The Physiology of Synapses, Springer-Verlag, Berlin.

Eccles, J. C., M. Ito, and J. Szentagothai (1967) The Cerebellum as a Neuronal Machine, Springer-Verlag, Berlin.

Getchell, T. V., and G. M. Shepherd (1975) Short-axon cells in the olfactory bulb: Dendrodendritic synaptic interactions. J. Physiol. (Lond.) 251: 523-548.

Hinds, J. W. (1970) Reciprocal and serial dendrodendritic synapses in the glomerular layer of the rat olfactory bulb. Brain Res. 17: 530534 .

Iwase, Y., and D. Lisenby (1965) Olfactory bulb responses in the turtle, with special reference to the deep negative spike. Jpn. J. Physiol. 15: $331-341$.

Jahr, C. E., and R. A. Nicoll (1982) An intracellular analysis of dendrodendritic inhibition in the turtle in vitro olfactory bulb. $J$. Physiol. (Lond.) 326: 213-234.

Kauer, J. S. (1981) Olfactory receptor cell staining using horseradish peroxidase. Anat. Rec. 200: 331-336.

Kuffler, S. W., and C. Eyzaguirre (1955) Synaptic inhibition in an isolated nerve cell. J. Gen. Physiol. 39: 155-184.

Land, L. J. (1973) Localized projection of olfactory nerves to rabbit olfactory bulb. Brain Res. 63: 153-166.

Land, L. J., and G. M. Shepherd (1974) Autoradiographic analysis of olfactory receptor projections in the rabbit. Brain Res. 80: 506-510.

Lüscher, H. -R., P. Ruenzel, and E. IIenneman (1983) Composite EPSPs in motoneurons of different sizes before and during PTP: Implications for transmission failure and its relief in Ia projections. J. Neurophysiol. 49: 269-289.

Mori, K., and G. M. Shepherd (1979) Synaptic excitation and longlasting inhibition of mitral cells in the in vitro turtle olfactory bulb. Brain Res. 172: 155-159.

Mori, K., and S. F. Takagi (1978) An intracellular study of dendrodendritic inhibitory synapses on mitral cells in the rabbit olfactory bulb. J. Physiol. (Lond.) 279: 569 588 .

Mori, K., M. C. Nowycky, and G. M. Shepherd (1981a) Electrophysi- 
ological analysis of mitral cells in isolated turtle olfactory bulb. J. Physiol. (Lond.) 314: 281-294.

Mori, K., M. C. Nowycky, and G. M. Shepherd (1981b) Analysis of synaptic potentials in mitral cells of the isolated turtle olfactory bulb. J. Physiol. (Lond.) 314: 295-309.

Mori, K., M. C. Nowycký, and G. M. Shepherd (1981c) Analysis of long duration inhibitory potential in mitral cells in the isolated turtle olfactory bulb. J. Physiol. (Lond.) 314: 311-320.

Mori, K., M. C. Nowycky, and G. M. Shepherd (1982) Impulse activity in presynaptic dendrites: Analysis of mitral cells in the isolated turtle olfactory bulb. J. Neurosci. 2: 497-502.

Nicoll, R. A. (1969) Inhibitory mechanisms in the rabbit olfactory bulb: Dendrodendritic mechanisms. Brain Res. 14: 157-172.

Nowycky, M. C., K. Mori, and G. M. Shepherd (1981) Blockade of synaptic inhibition reveals long-lasting synaptic excitation in isolated turtle olfactory bulb. J. Neurophysiol. 46: 649-658.

Orrego, F. (1961) The reptilian forebrain. II. Electrical activity in the olfactory bulb. Arch. Ital. Biol. 99: 446-465.

Phillips, C. G., T. P. S. Powell, and G. M. Shepherd (1963) Responses of mitral cells to stimulation of the lateral olfactory tract in the rabbit. J. Physiol. (Lond.) 168: 65-88.

Pinching, A. J., and T. P. S. Powell (1971) The neuropil in the glomeruli of the olfactory bulb. J. Cell Sci. 9: 347-377.

Price, J. L., and T. P. S. Powell (1970) The mitral and short axon cells of the olfactory bulb. J. Cell Sci. 7: 631-651.

Rall, W. (1977) Core conductor theory and cable properties of neurons. In Handbook of Physiology. Sect. 1: The Nervous System. Vol. I: Cellular Biology of Neurons, E. R. Kandel, ed., pp. 39-98, American Physiological Society, Bethesda, MD.

Rall, W., and G. M. Shepherd (1968) Theoretical reconstructions of field potentials and dendrodendritic synaptic interactions in olfactory bulb. J. Neurophysiol. 31: 884-915.

Ramón y Cajal, S. (1955) Studies on the Cerebral Cortex, Lloyd-Luke, London.

Reese, T. S., and M. W. Brightman (1970) Olfactory surface and central olfactory connections in some vertebrates. In CIBA Foundation Symposium on Taste and Smell in Vertebrates, G. E. W. Wolstenholm and J. Knight, eds., pp. 115-149, Churchill, London.

Shepherd, G. M. (1963) Neuronal systems controlling mitral cell excitability. J. Physiol. (Lond.) 168: 101-117.

Shepherd, G. M. (1971) Physiological evidence for dendrodendritic synaptic interactions in the rabbit's olfactory glomerulus. Brain Res. 32: $212-217$.

Shepherd, G. M. (1972) Synaptic organization of the mammalian olfactory bulb. Physiol. Rev. 52: 864-917.

Shepherd, G. M. (1977) The olfactory bulb: A simple system in the mammalian brain. In Handbook of Physiology. Sect. 1: The Nervous System, Vol. I, Part 2, pp. 945-968, American Physiological Society, Bethesda, MD.

Shepherd, G. M. (1979) The Synaptic Organization of the Brain, Ed. 2, Oxford University Press, New York.

Waldow, U., M. C. Nowycky, and G. M. Shepherd (1981) Evoked potential and single unit responses to olfactory nerve volleys in the isolated turtle olfactory bulb. Brain Res. 211: 267-283.

White, E. L. (1972) Synaptic organization in the olfactory glomerulus of the mouse. Brain Res. 37:69-80.

Yamamoto, C., T. Yamamoto, and K. Iwama (1963) The inhibitory system in the olfactory bulb studied by intracellular recording. J. Neurophysiol. 26: 403-415. 